\title{
Rescue In Vitro Fertilization Method for Legacy Stock of Frozen Mouse Sperm
}

\author{
Naomi NAKAGATA ${ }^{1)}$, Toru TAKEO ${ }^{1)}$, Kiyoko FUKUMOTO' ${ }^{1)}$, Yukie HARUGUCHI'), \\ Tomoko KONDO ${ }^{1)}$, Yumi TAKESHITA ${ }^{1)}$, Yuko NAKAMUTA ${ }^{1 \text { ), }}$, Tomoko UMENO ${ }^{1)}$ and \\ Shuuji TSUCHIYAMA ${ }^{1)}$ \\ 1) Division of Reproductive Engineering, Center for Animal Resources and Development (CARD), Kumamoto 860-0811,
Japan
}

\begin{abstract}
Sperm cryopreservation has been widely adopted for maintenance of the genetically engineered mouse (GEM). The cryopreserved sperm are being exchanged among many institutes worldwide. However, the recipients are not always able to obtain high fertilization rates with the frozen sperm shipped from senders. In this study, we cryopreserved mouse sperm via various methods and performed in vitro fertilization (IVF) in which the combination of methyl-beta-cyclodextrin for sperm preincubation and reduced glutathione for insemination was used (the MBCD-GSH IVF). In addition, frozen sperm sent from the Jackson Laboratory (USA) were thawed and used for IVF in the same manner. The fertilization rates of both the sperm cryopreserved via the methods applied in some countries and the cryopreserved GEM sperm improved when used with the MBCD-GSH IVF method. Therefore, we strongly believe that the MBCD-GSH IVF method brings about relatively high fertilization rates with any strain of frozen mouse sperm.
\end{abstract}

Key words: C57BL/6, Cryopreserved sperm, In vitro fertilization, Mouse, Transport

(J. Reprod. Dev. 60: 168-171, 2014)

O ver the past 20 years, a large number of mice with induced mutations have been produced worldwide [1-5]. Accordingly, many mouse repositories have been established in each country, while the exponential increase in mouse strains has necessitated the enlargement of existing mouse repositories and the establishment of new ones $[6,7]$. The increased centralized repository capacity and major advancements in sperm cryopreservation have made archiving strains relatively economical and reliable. Therefore, sperm freezing has become widely adopted for the maintenance of mice with induced mutations. As a result, frozen sperm samples are now exchanged among many institutes and universities worldwide [8, 9]. However, recipients are not always able to obtain high fertilization rates with frozen mouse sperm shipped from senders. This is obviously a major problem.

Recently, we established an in vitro fertilization (IVF) method using preincubation medium containing methyl-beta-cyclodextrin (MBCD) [10] and fertilization medium with reduced glutathione (GSH) [11] that yields high fertilizing ability for frozen sperm (MBCD-GSH IVF method).

In this study, we froze mouse sperm via the methods applied to maintain genetically engineered mice (GEM) even now in some countries and then used the MBCD-GSH IVF method to perform IVF using these frozen sperm. Mouse sperm were frozen via two different methods: one was a method using cryotubes developed by Sztein

Received: December 15, 2013

Accepted: January 3, 2014

Published online in J-STAGE: February 4, 2014

(C)2014 by the Society for Reproduction and Development

Correspondence: N Nakagata (e-mail: nakagata@kumamoto-u.ac.jp) et al. [12] (cryotube freezing method), and the other was a method using straws and cryoprotectant solution containing monothioglycerol (MTG) developed by Ostermeier et al. [13] (MTG-straw freezing method). After thawing, IVF was performed using the cryopreserved sperm. We carried out IVF using the method stipulated for each freezing method (cryotube IVF method and MTG-straw IVF method respectively), as well as using the MBCD-GSH IVF method. We then compared the fertilization rates for the cryopreserved sperm. In addition, GEM (C57BL/6 background) sperm samples frozen using the MTG-straw freezing method, which were sent to our center from the Jackson Laboratory (USA), were thawed, and the MBCD-GSH IVF method was performed using these sperm.

Table 1 and Table 2 show a comparison of fertilization rates and in vitro development of 2-cell embryos between the cryotube IVF method and the MBCD-GSH IVF method and between the MTG-straw IVF method and the MBCD-GSH IVF method respectively using the wild mouse strains. As shown in Tables 1 and 2, fertilization rates improved when the MBCD-GSH IVF method was used on sperm frozen via the cryotube freezing method and the MTG-straw freezing method $(3.9 \%$ and $33.0 \%$ for the cryotube IVF and MBCD-GSH IVF methods respectively; $37.4 \%$ and $88.3 \%$ for the MTG straw IVF and MBCD-GSH IVF methods respectively). Subsequently, fertilization rates using the MBCD-GSH IVF method for frozen GEM sperm were very high ( $94.1 \%$ and $95.8 \%$ respectively), while half of the transferred 2-cell embryos developed into live young for each strain (Table 3 ).

In our previous report, we demonstrated that the combination of MBCD for cryopreserved sperm preincubation and GSH for IVF (the MBCD-GSH IVF method) using fresh and cryopreserved oocytes produced very high fertilization rates $[11,14]$. In the present 
Table 1. Comparison of the rate of fertilization and in vitro development between the cryotube IVF method and the MBCD-GSH IVF method using sperm frozen by the cryotube freezing method

\begin{tabular}{lccccc}
\hline IVF method & Male No. & $\begin{array}{c}\text { No. of inseminated } \\
\text { oocytes }\end{array}$ & $\begin{array}{c}\text { No. of 2-cell } \\
\text { embryos (\%) }\end{array}$ & $\begin{array}{c}\text { No. of cultured } \\
\text { 2-cell embryos }\end{array}$ & $\begin{array}{c}\text { No. that developed to } \\
\text { blastocysts (\%) }\end{array}$ \\
\hline Cryotube & 1 & 39 & $0(0.0)$ & 0 & $0(0.0)$ \\
& 2 & 74 & $2(2.7)$ & 2 & $2(100.0)$ \\
& 3 & 35 & $2(5.7)$ & 2 & $1(50.0)$ \\
& 4 & 44 & $1(2.3)$ & 1 & $1(100.0)$ \\
& 5 & 91 & $6(6.6)$ & 6 & $4(66.7)$ \\
\hline MBCD-GSH & Total & 283 & $11(3.9)$ & 11 & $8(72.7)$ \\
& 1 & 40 & $14(35.0)$ & 14 & $10(71.4)$ \\
& 3 & 33 & $7(21.2)$ & 7 & $5(71.4)$ \\
& 4 & 44 & $20(45.5)$ & 20 & $16(80.0)$ \\
& 5 & 50 & $15(30.0)$ & 15 & $11(73.3)$ \\
& Total & 66 & $21(31.8)$ & 21 & $17(81.0)$ \\
\hline
\end{tabular}

Fertilization rate was calculated as the no. of 2-cell embryos divided by the no. of inseminated oocytes $\times 100$. Two-cell embryos were cultured to the blastocyst stage in vitro, and developmental rate was calculated as the no. of blastocysts divided by the no. of cultured 2 -cell embryos $\times 100 .{ }^{*} \mathrm{P}<0.05$ compared with the cryotube IVF method.

Table 2. Comparison of the rate of fertilization and in vitro development between the MTG straw IVF method and the MBCD-GSH IVF method using sperm frozen by the MTG-straw freezing method

\begin{tabular}{lccccc}
\hline IVF method & Male No. & $\begin{array}{c}\text { No. of inseminated } \\
\text { oocytes }\end{array}$ & $\begin{array}{c}\text { No. of 2-cell } \\
\text { embryos (\%) }\end{array}$ & $\begin{array}{c}\text { No. of cultured } \\
\text { 2-cell embryos }\end{array}$ & $\begin{array}{c}\text { No. that developed to } \\
\text { blastocysts (\%) }\end{array}$ \\
\hline MTG straw & 6 & 27 & $13(48.1)$ & 13 & $13(100.0)$ \\
& 7 & 63 & $18(28.6)$ & 18 & $17(94.4)$ \\
& 8 & 39 & $22(56.4)$ & 22 & $22(100.0)$ \\
& 9 & 57 & $18(31.6)$ & 18 & $17(94.4)$ \\
& 10 & 36 & $12(33.3)$ & 12 & $10(83.3)$ \\
\hline MBCD-GSH & Total & 222 & $83(37.4)$ & 83 & $79(95.2)$ \\
& 6 & 24 & $23(95.8)$ & 23 & $21(91.3)$ \\
& 7 & 41 & $30(73.2)$ & 30 & $26(86.7)$ \\
& 8 & 39 & $35(89.7)$ & 35 & $29(82.9)$ \\
& 9 & 29 & $28(96.6)$ & 28 & $23(82.1)$ \\
& 10 & 46 & $42(91.3)$ & 42 & $38(90.5)$ \\
\cline { 2 - 5 } & Total & 179 & $158(88.3)^{*}$ & 158 & $137(86.7)$ \\
\hline
\end{tabular}

Fertilization rate was calculated as the no. of 2-cell embryos divided by the no. of inseminated oocytes $\times 100$. Two-cell embryos were cultured to the blastocyst stage in vitro, and developmental rate was calculated as the no. that developed to blastocysts divided by the no. of cultured 2 -cell embryos $\times 100$. ${ }^{*} \mathrm{P}<0.05$ compared with the MTG straw IVF method.

Table 3. Production of normal young following transfer of embryos obtained by the MBCD-GSH IVF method using sperm frozen by the MTG-straw freezing method

\begin{tabular}{ccccc}
\hline $\begin{array}{c}\text { Strain of frozen } \\
\text { GEM sperm }\end{array}$ & $\begin{array}{c}\text { No. of inseminated } \\
\text { oocytes }\end{array}$ & $\begin{array}{c}\text { No. of 2-cell } \\
\text { embryos (\%) }\end{array}$ & $\begin{array}{c}\text { No. of transferrd } \\
\text { 2-cell embryos }\end{array}$ & $\begin{array}{c}\text { No. of live young } \\
(\%)\end{array}$ \\
\hline 1 & 185 & $174(94.1)$ & 60 & $30(50)$ \\
2 & 165 & $158(95.8)$ & 60 & $30(50)$ \\
\hline
\end{tabular}

Fertilization rate was calculated as the no. of 2-cell embryos divided by the no. of inseminated oocytes $\times 100$. Two-cell embryos were transferred to recipients, and birth rate was calculated as the no. of 2-cell embryos divided by the no. of transferred 2-cell embryos $\times 100$. 
A

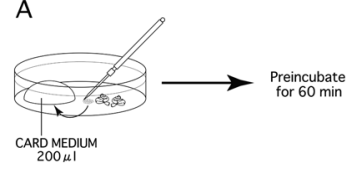

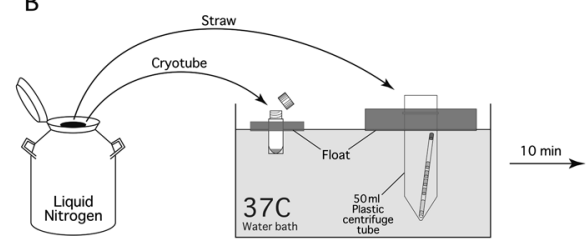

C
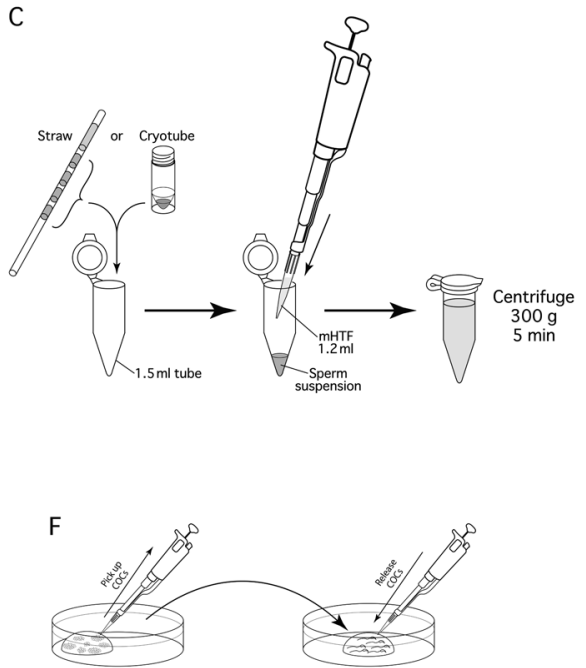

D
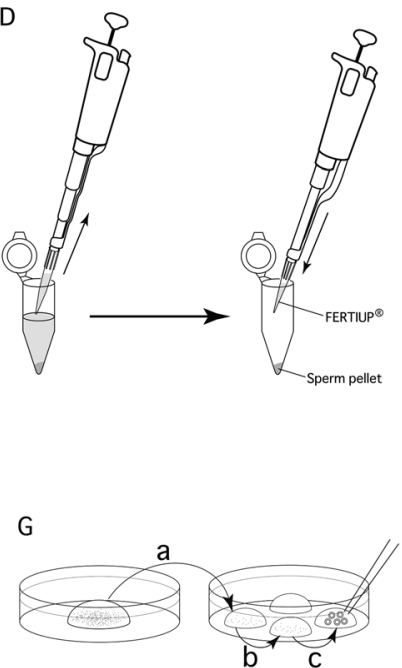

E

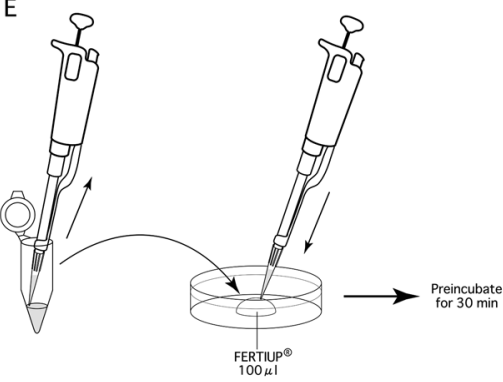

$\mathrm{H}$

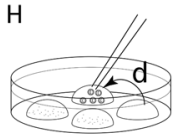

Fig. 1. Rescue IVF protocol using cryopreserved mouse sperm. A: Transfer cumulus oocytes complexes (COCs) into a drop of CARD MEDIUM. B: Remove a frozen sperm sample and immerse it in a water bath maintained at $37 \mathrm{C}$. C: Transfer the sperm suspension into a tube, and add mHTF to the tube containing the sperm suspension. Thereafter, immediately centrifuge the tube. D: Remove the supernatant and add FERTIUP® mouse sperm preincubation medium into the tube. E: After pipetting gently, transfer the entire sperm suspension into the drop of FERTIUP ${ }^{\circledR}$ preincubation medium, and incubate the sperm in a $\mathrm{CO}_{2}$ incubator. F: Introduce the preincubated COCs into the drop of sperm suspension, and incubate them in the $\mathrm{CO}_{2}$ incubator. G: After $3 \mathrm{~h}$, wash the oocytes three times in drops of $\mathrm{mHTF}$, and then culture them in the $\mathrm{CO}_{2}$ incubator. H: Twenty-four hours after insemination, transfer just the obtained 2-cell stage embryos to a fourth drop of mHTF. (See http://www.kyudo.co.jp/Fertiup/methods.htm).

study, we also showed that fertilization rates for sperm frozen by the methods adopted even now in some countries $[12,13]$ can be improved using the MBCD-GSH IVF method [11]. Therefore, we believe strongly that the MBCD-GSH IVF method achieves relatively high fertilization rates with any frozen mouse sperm, and especially with legacy stocks of frozen sperm.

\section{Methods}

\section{Animals}

C57BL/6 mice were purchased from CLEA Japan (Tokyo, Japan) and Charles River Laboratories Japan (Kanagawa, Japan) for use as oocyte and sperm donors. ICR mice (CLEA Japan) were used as recipients for the transfer of 2-cell embryos. All animals were kept under a $12 \mathrm{~h}$ dark-light cycle (lights on: 0700-1900 h) at a constant temperature of $22 \pm 1 \mathrm{C}$ with free access to food and water. All animal experiments were approved by the Animal Care and Use Committee at Kumamoto University.

\section{Sperm freezing and thawing}

The sperm were collected from the vasa deferentia and caudae epididymides of three-month-old male mice and were frozen via the cryotube freezing method [12] and the MTG-straw freezing method [13]. Frozen samples were rapidly thawed by transferring them from liquid nitrogen into a $37 \mathrm{C}$ water bath. Subsequently, the frozen-thawed sperm were used for IVF. Half of the sperm were used for either the cryotube IVF method or the MTG-straw IVF method $[12,13]$, and half of the remaining samples were used for the MBCD-GSH IVF method [11].

\section{IVF}

The procedures for the cryotube IVF method and the MTG-straw IVF method were as described by Sztein et al. [12] and by Ostermeier et al. [13] respectively. The MBCD-GSH IVF method is shown in Fig. 1 . The oocytes used were obtained from females at 2-3 months of age. Females were induced to superovulate via injections of 7.5 IU PMSG (ASKA Pharmaceutical, Tokyo, Japan) and 7.5 IU human chorionic gonadotropin (ASKA Pharmaceutical) administered $48 \mathrm{~h}$ apart. Intact cumulus oocyte complexes (COCs) were released from the excised oviducts of superovulated females into a drop (200 $\mu \mathrm{l})$ of CARD MEDIUM (Kyudo, Saga, Japan) covered with paraffin oil in a plastic dish (Cat.\#No.\#430588, Corning, Corning, NY, USA) 15-17 
$\mathrm{h}$ after hCG and were preincubated for $60 \mathrm{~min}$ (Fig. 1-A). Sperm samples frozen via the cryotube freezing method and the MTG-straw freezing method were removed from the liquid nitrogen and immersed in a $50 \mathrm{ml}$ plastic centrifuge tube (in a water bath maintained at 37 C) for $10 \mathrm{~min}$ (Fig. 1-B). After thawing, the sperm suspension in a cryotube or a straw was transferred into a $1.5 \mathrm{ml}$ tube (Cat. No. 509-GRD, BM Equipment, Tokyo, Japan), and $1.2 \mathrm{ml}$ of $\mathrm{mHTF}$ [15] was added slowly to the tube containing the sperm suspension. Thereafter, the tube was immediately centrifuged at $300 \mathrm{~g}$ for $5 \mathrm{~min}$ (Fig. 1-C). After centrifugation, as much supernatant was removed as possible, and an appropriate amount of FERTIUP ${ }^{\circledR}$ mouse sperm preincubation medium (Kyudo) was added to the tube (the final volume was adjusted to $100 \mu \mathrm{l}$ ) (Fig. 1-D). After pipetting gently, the entire sperm suspension $(100 \mu \mathrm{l})$ was transferred into a drop of FERTIUP ${ }^{\circledR}$ mouse sperm preincubation medium $(100 \mu \mathrm{l})$ covered with paraffin oil in a dish. The dish was placed in an incubator $(37 \mathrm{C}$, $5 \% \mathrm{CO}_{2}$ in air) for $30 \mathrm{~min}$ (Fig. 1-E). Then, the preincubated COCs were sucked up from the drop of CARD MEDIUM using a tip (Cat. No.\#17021-1, NIPPON Genetics, Tokyo, Japan) and introduced into the drop of sperm suspension (insemination) (Fig. 1-F). The COCs were incubated in an incubator. After $3 \mathrm{~h}$, the inseminated oocytes were washed three times in drops $(80 \mu \mathrm{l})$ of mHTF covered with paraffin oil in a dish (Fig. 1-G (a-c)), and cultured at $37 \mathrm{C}$ with $5 \% \mathrm{CO}_{2}$. Seven to eight hours after insemination, the formation of pronuclei was observed under a phase contrast microscopy. Twentyfour hours after insemination, just the obtained 2-cell stage embryos were transferred to a 4th drop of mHTF (Fig. 1-H (d)). Fertilization rates were calculated as the total number of 2-cell embryos divided by the total number of inseminated oocytes, multiplied by 100 . All 2-cell embryos were cultured to the blastocyst stage in KSOM [16]. In addition, GEM (C57BL/6 background) sperm frozen via the MTG-straw freezing method, which were sent to our center from the Jackson Laboratory (USA), were thawed and used for IVF in the same manner. A portion of the 2-cell embryos were transferred into the oviducts of ICR females (10 embryos/oviduct) on the day a vaginal plug was found (day 1 of pseudopregnancy) using the method of embryo transfer through the wall of the oviduct [17]. After 19 days, the number of offspring was recorded.

\section{Statistical analysis}

Statistical analysis was performed using the GraphPad Prism version 5.0 software (GraphPad, San Diego, CA, USA). Group results were compared using the Student's $t$-test after arcsine transformation of the percentage data; $\mathrm{P}<0.05$ was considered significant.

\section{Acknowledgment}

This study was supported by a Grant-in-Aid for the Fundamental Technologies Upgrading Program, National BioResource Project (NBRP), of the Ministry of Education, Culture, Sports, Science and Technology (MEXT), Japan.

\section{References}

1. Jaenisch R. Transgenic animals. Science 1988; 240: 1468-1474. [Medline] [CrossRef]

2. Bedell MA, Largaespada DA, Jenkins NA, Copeland NG. Mouse models of human disease. Part II: recent progress and future directions. Genes Dev 1997; 11: 11-43. [Medline] [CrossRef]

3. Simpson EM, Linder CC, Sargent EE, Davisson MT, Mobraaten LE, Sharp JJ. Genetic variation among 129 substrains and its importance for targeted mutagenesis in mice. Nat Genet 1997; 16: 19-27. [Medline] [CrossRef]

4. Brown SDM, Nolan PM. Mouse mutagenesis-systematic studies of mammalian gene function. Hum Mol Genet 1998; 7: 1627-1633. [Medline] [CrossRef]

5. Hrabé de Angelis M, Balling R. Large scale ENU screens in the mouse: genetics meets genomics. Mutat Res 1998; 400: 25-32. [Medline] [CrossRef]

6. Davisson M. FIMRe: Federation of International Mouse Resources: global networking of resource centers. Mamm Genome 2006; 17: 363-364. [Medline] [CrossRef]

7. Donahue LR, Hrabe de Angelis M, Hagn M, Franklin C, Lloyd KC, Magnuson T, McKerlie C, Nakagata N, Obata Y, Read S, Wurst W, Hörlein A, Davisson MT. Centralized mouse repositories. Mamm Genome 2012; 23: 559-571. [Medline] [CrossRef]

8. Du Y, Xie W, Liu C. Strategies and considerations for distributing and recovering mouse lines. Methods Enzymol 2010; 476: 37-52. [Medline] [CrossRef]

9. Takahashi H, Liu C. Archiving and distributing mouse lines by sperm cryopreservation, IVF, and embryo transfer. Methods Enzymol 2010; 476: 53-69. [Medline] [CrossRef]

10. Takeo T, Hoshii T, Kondo Y, Toyodome H, Arima H, Yamamura K, Irie T, Nakagata N. Methyl-beta-cyclodextrin improves fertilizing ability of C57BL/6 mouse sperm after freezing and thawing by facilitating cholesterol efflux from the cells. Biol Reprod 2008; 78: 546-551. [Medline] [CrossRef]

11. Takeo T, Nakagata N. Reduced glutathione enhances fertility of frozen/thawed C57BL/6 mouse sperm after exposure to methyl-beta-cyclodextrin. Biol Reprod 2011; 85: $1066-$ 1072. [Medline] [CrossRef]

12. Sztein JM, Farley JS, Mobraaten LE. In vitro fertilization with cryopreserved inbred mouse sperm. Biol Reprod 2000; 63: 1774-1780. [Medline] [CrossRef]

13. Ostermeier GC, Wiles MV, Farley JS, Taft RA. Conserving, distributing and managing genetically modified mouse lines by sperm cryopreservation. PLOS ONE 2008; 3: e2792. [Medline] [CrossRef]

14. Nakagata N, Takeo T, Fukumoto K, Kondo T, Haruguchi Y, Takeshita Y, Nakamuta Y, Matsunaga H, Tsuchiyama S, Ishizuka Y, Araki K. Applications of cryopreserved unfertilized mouse oocytes for in vitro fertilization. Cryobiology 2013; 67: 188-192. [Medline] [CrossRef]

15. Kito S, Hayao T, Noguchi-Kawasaki Y, Ohta Y, Hideki U, Tateno S. Improved in vitro fertilization and development by use of modified human tubal fluid and applicability of pronucleate embryos for cryopreservation by rapid freezing in inbred mice. Comp Med 2004; 54: 564-570. [Medline]

16. Ho Y, Wigglesworth K, Eppig JJ, Schultz RM. Preimplantation development of mouse embryos in KSOM: augmentation by amino acids and analysis of gene expression. Mol Reprod Dev 1995; 41: 232-238. [Medline] [CrossRef]

17. Nakagata N. Embryo transfer through the wall of the fallopian tube in mice. Jikken Dobutsu 1992; 41: 387-388 (in Japanese). [Medline] 